\title{
TEAPET: Desenvolvendo Pets Digitais Voltados para Indivíduos Portadores do Transtorno do Espectro Autista
}

\author{
Victória O. Gomes ${ }^{1}$, Victor T. Sarinho ${ }^{1}$ \\ ${ }^{1}$ Laboratório de Entretenimento Digital Aplicado - LEnDA \\ Universidade Estadual de Feira de Santana - UEFS \\ Feira de Santana - Bahia - Brasil \\ victoria.oliveiragomes@gmail.com, vsarinho@uefs.br
}

\begin{abstract}
The ability to interact with other people and establish relationships is an extremely important skill for living in society. To build these bonds, it is important to know how to interpret emotional signals, as well as how to respond to them in an appropriate way. This aspect, however, constitutes a deficit in most individuals with Autism Spectrum Disorder (ASD), which makes these people's relationships more limited than neurotypic ones. In order to work in this skill, this article proposes the development of TEAPET, a game that uses technologies and learning that can be passed on with the help of a virtual pet so that, through the association between the pet's facial expressions and their needs, the child evolves in relation to the interpretation of other people emotions.
\end{abstract}

Resumo. A habilidade de interagir com outras pessoas e estabelecer relações constitui uma competência extremamente importante para viver em sociedade. Para a construção desses laços, é importante saber interpretar sinais emocionais, bem como responder a estes de maneira apropriada. Esse aspecto, no entanto, constitui um déficit em grande parte dos indivíduos portadores do Transtorno do Espectro Autista (TEA), o que faz com que estas pessoas, muitas vezes, possuam relacionamentos mais limitados do que os neurotípicos. A fim de trabalhar essa habilidade, este artigo propõe o desenvolvimento do TEAPET, um jogo que se utiliza das tecnologias e dos aprendizados que podem ser passados com o auxílio de um animal de estimação virtual para que, através da associação entre as expressões faciais do pet e suas necessidades, a criança evolua em relação a interpretação das emoções de terceiros.

\section{Introdução}

O Transtorno do Espectro Autista (TEA) constitui uma desordem neurológica definida do ponto de vista comportamental, o qual apresenta etiologias múltiplas e se caracteriza por diferentes níveis de gravidade. O portador deste transtorno apresenta padrões restritos e repetitivos de comportamento, interesses ou atividades, bem como déficits na comunicação e interação social, os quais são observados em múltiplos contextos [Association et al. 2013]. Além disso, manifestam dificuldades relacionadas ao desenvolvimento, manutenção e compreensão de relacionamentos.

Uma das principais peculiaridades dispostas por indivíduos portadores do TEA, que afeta diretamente as relações interpessoais e o estabelecimento de relacionamentos, é a dificuldade em processar, produzir e responder a sinais emocionais 
[Travis and Sigman 1998]. Ainda assim, embora possuam esses déficits, crianças que vivem neste espectro são capazes de estabelecer relacionamentos com familiares e amigos, apesar destes serem, frequentemente, mais limitados do que o de crianças neurotípicas.

Diversos tipos de abordagens vêm sendo utilizadas a fim de minimizar a expressão destas características apresentadas por estes indivíduos, tendo como objetivo principal viabilizar uma melhor qualidade de vida para os mesmos. Dentre estas abordagens, tem-se o uso da tecnologia, que vem maximizando os benefícios promovidos na área da saúde e, mais especificamente, na área do TEA. Seu uso facilita o tratamento de portadores deste transtorno, além de promover o desenvolvimento cognitivo destes, facilitando o processo de aquisição de conhecimento.

Levando esses fatos em consideração, este trabalho propõe o desenvolvimento de um jogo digital sério aplicado à saúde, o qual será capaz de trabalhar aspectos relacionados a interações sociais. Tal software será chamado de TEAPET, e sua confecção se dará na forma de um pet digital, uma aplicação inspirada na interação humana com animais [Donath 2004]. Para isto, tomaremos como base as características gerais que um jogo voltado para portadores do TEA deve possuir, as quais serão retiradas de um questionário previamente desenvolvido [Aguiar et al. 2018].

Vale salientar que adotar, cuidar e brincar com animais online força, de uma forma divertida, a pensar no mundo através dos olhos e das necessidades dos mesmos, buscando entendê-lo através de uma comunicação não-verbal baseada em gestos e expressões faciais [Altschuler 2008]. Assim, o formato de pet digital foi escolhido, além dos motivos descritos anteriormente, por conta do fato que pets digitais possuem grande importância no desenvolvimento de habilidades em geral e podem atuar em uma vasta gama de áreas [Donath 2004].

\section{Metodologia}

O uso do computador como objeto de aprendizagem voltado para o TEA se mostra relevante no desenvolvimento e na promoção de relações interpessoais [Passerino 2005], e o estabelecimento destas é um aspecto extremamente importante da vida humana [Travis and Sigman 1998]. No entanto, no que tange essa utilização da tecnologia em prol de portadores do TEA, seu uso deve ser feito cautelosamente [Fletcher-Watson 2014]. Dadas as suas peculiaridades comportamentais, se faz necessária a realização de um estudo acerca das possíveis respostas que os mesmos podem fornecer quando receberem estímulos específicos, a fim de evitar resultados indesejáveis que venham a acarretar em uma regressão no quadro do indivíduo.

Assim, para a idealização do TEAPET levamos em consideração um questionário levantado posteriormente [Aguiar et al. 2018], buscando minimizar a incidência de elementos distrativos no jogo, fornecer um feedback em relação as ações realizadas de maneira sutil, a fim de não desinteressar o jogador e, ao mesmo tempo, conseguir transmitir o conhecimento associado a interpretação de expressões faciais. Baseando-se nesses aspectos, a escolha de cores foi feita, em grande parte do jogo, a partir de variações de um mesmo tom, visando algo mais monocromático, onde os tons mais escuros são utilizados nas partes que devem ter mais atenção da criança, minimizando assim elementos distrativos. 
Em relação a dinâmica do jogo, a criança terá a missão de escolher o pet que deseja adotar e cuidar, o que inclui alimentá-lo, dar banho, brincar com ele, entre outros. Para realizar essa atividade de brincar com seu animal virtual, serão disponibilizados minigames, os quais serão confeccionados também com base nos critérios e dinâmicas identificados previamente [Aguiar et al. 2018].

Além disso, a fim de direcionar as dinâmicas utilizadas no jogo, o método TEACHH foi utilizado, o qual objetiva auxiliar o indivíduo autista na aquisição de novas habilidades [Moreira and Hirschfeld 2005]. Essa metodologia infere que os pontos chaves a serem considerados para uma transmissão de conhecimento efetiva com os portadores do TEA seriam: 1) utilizar cada espaço para funções específicas; 2) realizar as atividades de maneira que as crianças consigam prever o que lhes será exigido e 3) utilizar o apoio de materiais visuais, como cartões, murais, entre outros.

Assim, no início do jogo é explicitado para a criança quais cuidados esperamos que ela forneça para o seu pet e em quais momentos, algo que é feito através do uso de imagens uma vez que já se provou ser a melhor maneira para se comunicar com portadores do TEA [Barbosa 2009]. Para promover essas interações, existem ambientes diversos, sendo cada um deles focado em uma atividade, tais como: uma cozinha onde deverá ser feita a alimentação, um enfermaria para cuidados veterinários, um banheiro para que o pet faça suas necessidades, entre outros. Através das expressões faciais que o pet irá mostrar, o que dependerá da qualidade dos cuidados que estará recebendo, juntamente com a interpretação dos seus níveis de satisfação mostrado, almeja-se promover um aumento na habilidade de processar sinais emocionais e, consequentemente, responder e produzi-los.

Em relação a confecção do jogo, a Godot Engine (versão 3.2) foi utilizada. Trata-se de um motor de jogo cuja programação é realizada em GDScript, baseado em Phyton, onde cada ambiente do jogo é definido como uma cena. Ela permite que o jogo desenvolvido seja exportado para diversas plataformas diferentes, sendo o Android a plataforma alvo do TEAPET.

\section{Resultados e Discussão}

Na Figura 1(a), podemos observar a tela inicial do TEAPET. Visando simplificar a interação da criança, o jogador pode realizar três ações principais a partir dos botões em destaque: iniciar um novo jogo, continuar um anterior ou verificar as instruções. Os demais botões são utilizados para dar os créditos aos recursos de terceiros utilizados no jogo e para permitir a desativação de efeitos sonoros e música de fundo, visto que estes podem se tornar incômodos a indivíduos específicos.

Ao escolher iniciar um novo jogo, a criança irá escolher o pet que deseja adotar e, por fim, será redirecionada para a tela do jogo. Por conta de necessidade de manter o foco da criança em uma atividade específica, o ambiente do jogo foi dividido em seis: um ambiente 1) para alimentação, 2) para fazer higenização, 3) para brincar, 4) para consultas com o veterinário, 5) para dormir e 6) para andar ao ar livre.

$\mathrm{Na}$ Figura 1(b), por exemplo, podemos observar o local designado para a alimentação do pet. Nela, é possível que o jogador compre as mais diversas comidas para dar ao seu animalzinho, utilizando, para tanto, moedas que podem ser adquiridas ao jogar os minigames disponíveis no jogo. É nesse local também que o pet deverá tomar líquidos, como água, suco, etc. 


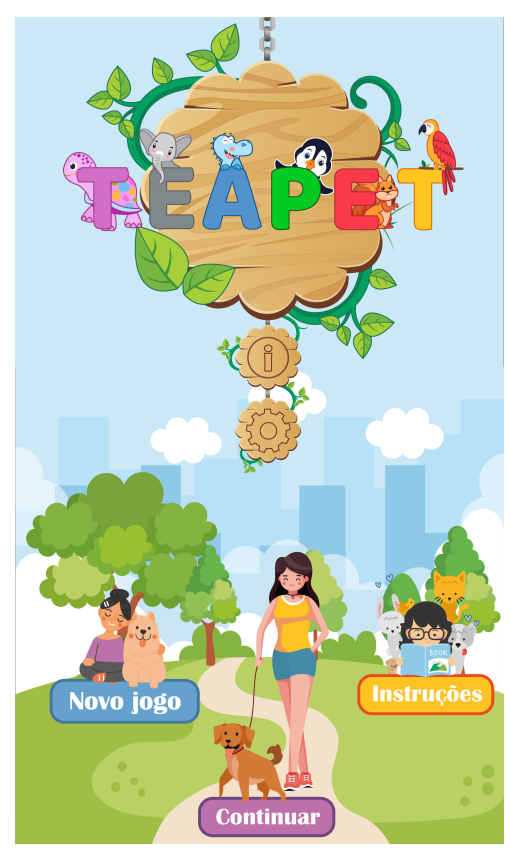

(a) Tela inicial do jogo.

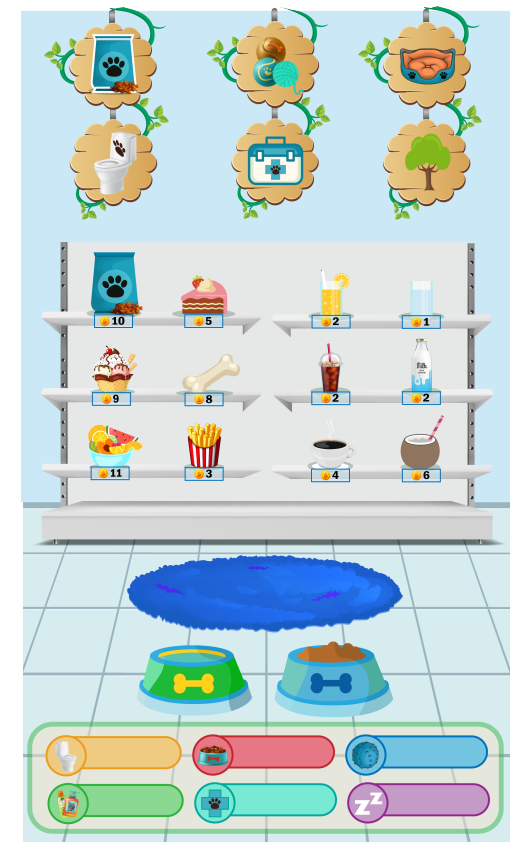

(b) Tela da cozinha.

Figure 1. Tela de inicial e a cozinha do TEAPET.

Dada a importância de levar seu animal de estimação ao veterinário com uma certa periodicidade, o jogo conta também com uma espécie de enfermaria, como observado na Figura 2(a), onde o pet será examinado por um profissional, tomará suas vacinas e medicações necessárias, entre outros. Na tela do banheiro, exibida na Figura 2(b), o pet irá fazer suas necessidades e higienização.

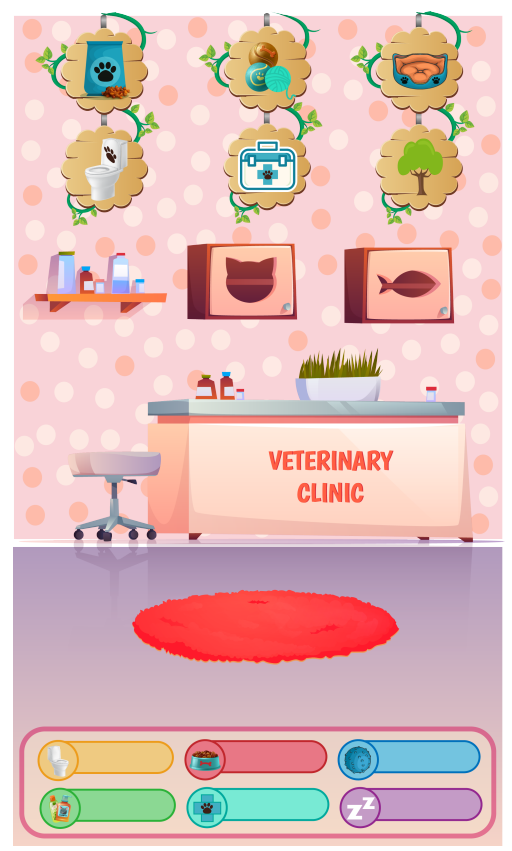

(a) Tela da enfermaria.

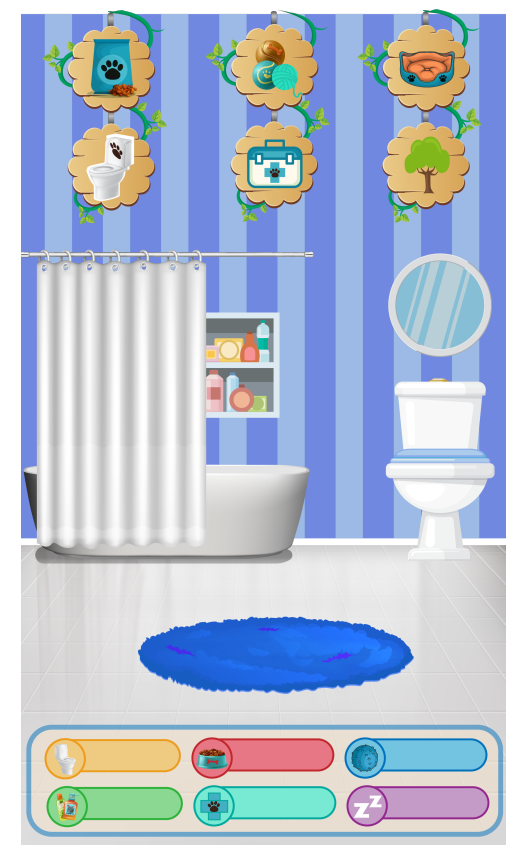

(b) Tela do banheiro.

Figure 2. Banheiro e enfermaria do TEAPET. 
Para alternar entre os ambientes, temos seis botões dispostos na parte superior da tela e, para interagir com cada um desses ambientes descritos e também com as demais, é necessário apenas realizar cliques simples nos locais relativos a ação que deseja realizar: para tomar um banho, por exemplo, basta clicar na banheira. Essa interação simples foi selecionada visando não exigir uma coordenação motora muito avançada para a criança que está brincando.

Como mostrado nas três imagens de ambientes pertencentes ao TEAPET que foram exemplificadas, todas possuem um marcador embaixo, o qual é exibido mais detalhadamente na Figura 3. Ele é responsável por mostrar ao jogador o quão satisfeitas se encontram cada uma das necessidades do pet, onde espera-se que, ao associar o nível da necessidade com a expressão do pet, a criança desenvolva uma maior habilidade em relação a interpretação de expressões faciais. Nesses marcadores, temos que: o amarelo está relacionado com a necessidade de ir ao banheiro; o verde, com a higiene; o vermelho, com a alimentação; o verde-água com a saúde; o azul com a diversão; e o lilás, por fim, com o sono do pet.

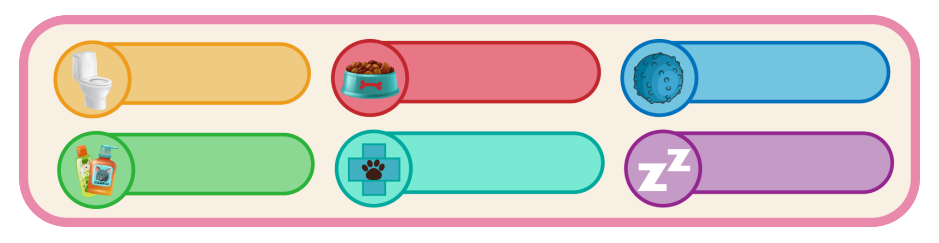

Figure 3. Marcadores relativos as necessidades do pet.

Em relação aos minigames, atualmente três estão disponíveis, sendo que todos eles são baseados em dinâmicas de cliques simples:

- Minigame 1: o pet se encontra em um skate e vai andando pelo mapa, e o jogador deve clicar para que ele pule sempre que houver um buraco a sua frente;

- Minigame 2: temos um jogo da memória, onde o jogador deve clicar em uma carta para fazer com que ela se vire, buscando formar pares de cartas iguais;

- Minigame 3: há uma chuva de comidinhas, e o jogador deverá clicar na tela para trocar a posição do seu pet, a fim de colocá-lo no local exato onde os alimentos estiverem caindo, os quais mudarão de lugar constantemente.

Diferente dos pets digitais comuns, o TEAPET não se atém a cuidar apenas de animais de estimação. Na Figura 4, por exemplo, podemos observar as emoções exibidas por um dos pets do jogo, as quais serão exibidas para o jogador a depender da maneira que ele tratar o pet.

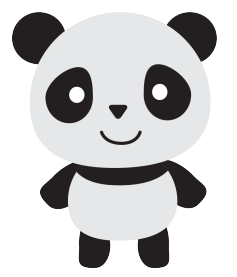

(a) Feliz

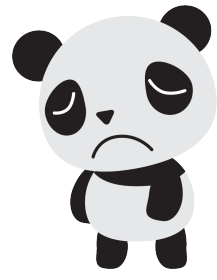

(b) Triste

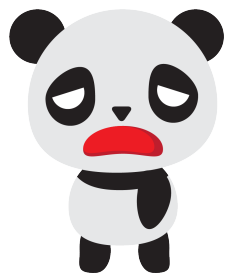

(c) Cansado

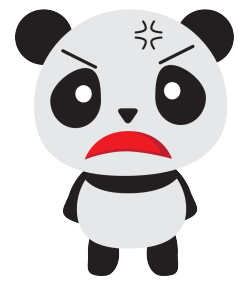

(d) Irritado

Figure 4. Sprites com as emoções utilizadas para o Panda. 


\section{Conclusões e Trabalhos Futuros}

Este artigo descreveu o desenvolvimento do TEAPET, um jogo sério voltado para a saúde baseado no formato de pets digitais. Tal jogo auxiliará portadores do TEA no processamento, resposta e produção de sinais emocionais, visando facilitar a integração e interação social dessas crianças com o meio onde se encontram, dado que estes são extremamente importantes para a vida em sociedade.

Além de auxiliar as crianças, almeja-se que tal ferramenta possa contribuir com os pais e profissionais que se dedicam a aplicar intervenções em tais indivíduos, fornecendo uma maneira mais prática de se trabalhar a habilidade relativa a interpretação de emoções e, ao mesmo tempo, divertindo a criança. Como trabalhos futuros, almeja-se adicionar mais opções de minigames ao jogo e uma maior variedade de pets. Isso, no entanto, será feito após a realização de uma validação com o público alvo, para que identifiquemos melhorias a serem feitas no estado atual do jogo antes de prosseguir para a adição de novas funcionalidades.

\section{Agradecimentos}

Agradecemos ao Programa de Bolsas de Iniciação Científica da Fundação de Amparo à Pesquisa do Estado da Bahia (PIBIC/FAPESB) pela concessão da Bolsa de Pesquisa para a realização deste projeto.

\section{References}

Aguiar, E., Pedreira, L. O., Gomes, V., and Sarinho, V. (2018). Avaliando jogos digitais educativos para indivíduos portadores do transtorno do espectro autista. In Brazilian Symposium on Computers in Education (Simpósio Brasileiro de Informática na Educação-SBIE), volume 29, page 1830.

Altschuler, E. L. (2008). Play with online virtual pets as a method to improve mirror neuron and real world functioning in autistic children. Medical hypotheses, 70(4):748-749.

Association, A. P. et al. (2013). Diagnostic and statistical manual of mental disorders (DSM-5®). American Psychiatric Pub.

Barbosa, H. F. A. (2009). Análise do recurso a novas tecnologias no ensino de autistas. $\mathrm{PhD}$ thesis, Instituto Politécnico do Porto. Instituto Superior de Engenharia do Porto.

Donath, J. (2004). Artificial pets: Simple behaviors elicit complex attachments.

Fletcher-Watson, S. (2014). A targeted review of computer-assisted learning for people with autism spectrum disorder: Towards a consistent methodology. Review Journal of Autism and Developmental Disorders, 1(2):87-100.

Moreira, P. S. T. and Hirschfeld, K. (2005). Autismo: a difícil arte de educar. Guaíba: Universidade Luterana do Brasil-ULBRA-Campus Guaíba.

Passerino, L. M. (2005). Pessoas com autismo em ambientes digitais de aprendizagem: estudo dos processos de interação social e mediação.

Travis, L. L. and Sigman, M. (1998). Social deficits and interpersonal relationships in autism. Mental Retardation and Developmental Disabilities Research Reviews, 4(2):65-72. 